\title{
Does pelvic asymmetry in children is related to pelvic asymmetry of their parents?
}

Maciej J Dluski

From The 10th Meeting of the International Research Society of Spinal Deformities (IRSSD 2014 Sapporo) Sapporo, Japan. 29 June - 2 July 2014

\section{Objectives}

Asymmetry within the pelvic structure can lead to a cascade of postural compensations throughout the spine, predisposing people to recurrent somatic dysfunction and decreased functionality. As a basic structural element, the pelvis should be fully symmetric with respect to the sagittal plane. However, many studies conducted by different researchers showed, that the asymmetry of the pelvis is a very common case. This asymmetry was recorded as a result of various types of measurements made on the basis of $\mathrm{X}$-rays, TK as well as sectional preparations. The reason for this was seen in the shortened one of the lower limbs or the lumbar spine pathology.

The aim of this paper is to answer the question: If there is any relationship between pelvic asymmetry in children and pelvic asymmetry of their parents?

\section{Material and methods}

A total of 180 volunteer subjects were included in the study and classified into 60 groups. Each group included one child (aged 3-17 years, 30 males and 30 females)

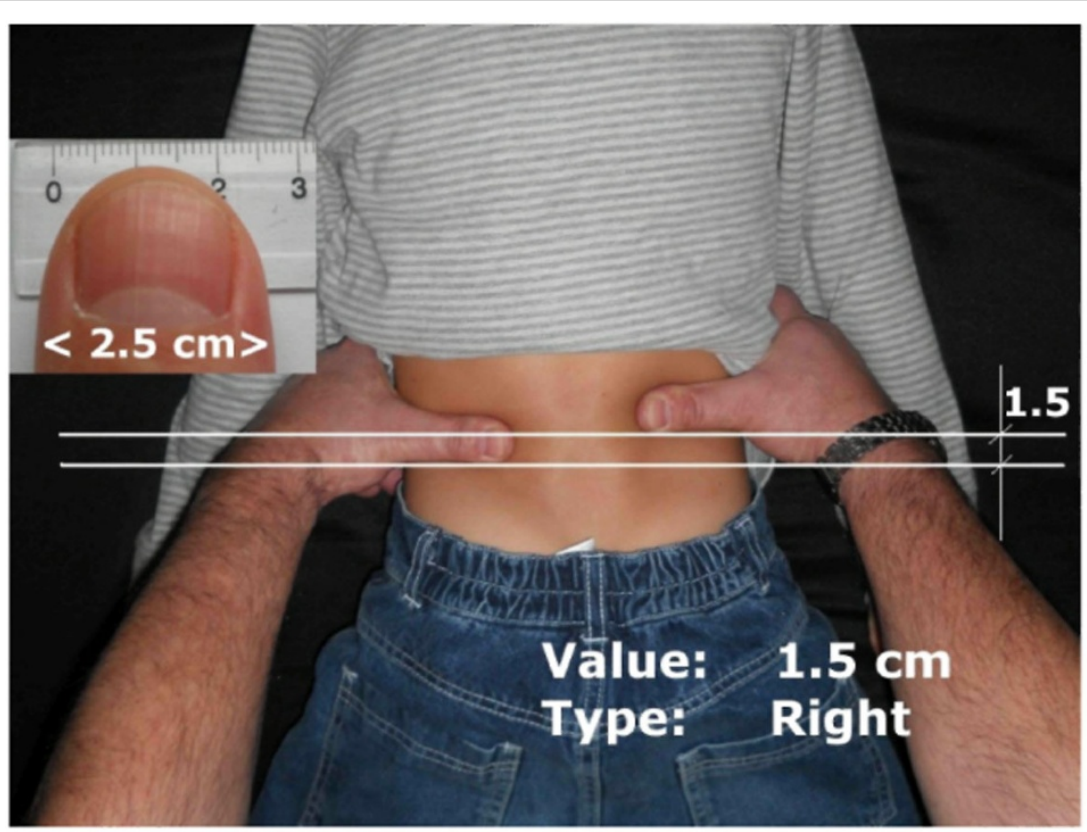

Figure 1 The method of measurements (child's pelvic)

ART- Centre of Natural Therapies, Rzeszow, Poland 
Table 1 Measurement of the pelvis (type). Number and percentage of cases

\begin{tabular}{ccccccc}
\hline Type & \multicolumn{2}{c}{ Child } & \multicolumn{2}{c}{ Mother } & \multicolumn{2}{c}{ Father } \\
\hline Neutral & 7 & $11 \%$ & 8 & $13 \%$ & 28 & $46 \%$ \\
\hline Left ${ }^{*}$ & 2 & $3 \%$ & 0 & $0 \%$ & 1 & $2 \%$ \\
\hline Right * & 51 & $86 \%$ & 52 & $87 \%$ & 31 & $52 \%$ \\
\hline *
\end{tabular}

* iliac crest more distant from the investigator

Table 2 Correlation between pelvic asymmetry/symmetry in children and their parents (value and type)

\begin{tabular}{ccc}
\hline Child & Mother & Father \\
\hline Value & 0.65 & -0.24 \\
\hline Type & 0.93 & -0.34 \\
\hline
\end{tabular}

Marked correlations are significant at $p<0,05$

and its biological parents; mothers aged 29 to 50 and fathers aged 30 to 52 . To determine the asymmetry of the pelvis, each person was tested in the same manner. The palpation examination of anatomical landmarks (the highest points of iliac crest) has been carried out in a symmetrical prone position of the tested one. Approved measurement accuracy was 0.5 centimeters. Type of asymmetry marked as the term, which iliac crest was more distant from the investigator. Method of the study is shown in a Figure 1.

\section{Results}

The results of measurements of pelvic symmetry are presented in Tables 1 and 2 .

\section{Conclusions}

The carried out research shows that there is a relationship between the laying of the pelvic bones of the child and mother. Correlation of the measured displacement is significant and amounts to 0.65. In terms of type of asymmetry is a very strong correlation and its value is equal to 0.93 . The compound of symmetry of the pelvis of the child and father is negligible. Although the correlation is negative (respectively - 0.24 and - 0.34, inverse correlation), the strength of this correlation is small and irrelevant. The results encourage further exploration. The problem is still open.

\section{Consent}

Written informed consent was obtained from the patient for the image(s) used in this study. A copy of the written consent is available for review by the Editor of this journal.
Published: 19 January 2015

\section{doi:10.1186/1748-7161-10-S1-P14}

Cite this article as: Dluski: Does pelvic asymmetry in children is related

to pelvic asymmetry of their parents? Scoliosis 2015 10(Suppl 1):P14.
Submit your next manuscript to BioMed Central and take full advantage of:

- Convenient online submission

- Thorough peer review

- No space constraints or color figure charges

- Immediate publication on acceptance

- Inclusion in PubMed, CAS, Scopus and Google Scholar

- Research which is freely available for redistribution

Submit your manuscript at www.biomedcentral.com/submit 